\title{
More than Education: Openness to Experience Contributes to Cognitive Reserve in Older Adulthood
}

\author{
Emilie I Franchow*, Yana Suchy, Sommer R Thorgusen and Paula Williams \\ Department of Psychology, University of Utah, USA
}

\begin{abstract}
Cognitive reserve $(\mathrm{CR})$ is a well-known indicator of resilience to cognitive decline in older adulthood. Although higher education is the most widely-recognized contributor to $\mathrm{CR}$, research suggests that the personality trait Openness to Experience might also contribute to reserve in later life. The purpose of this study was to examine whether the personality trait Openness contributes uniquely and independently to CR (above and beyond education). 72 adults $(M=70.46$ years old, $S D=6.82$ ) completed the WAIS-III Information subtest (measuring CR), the NEO Personality Inventory-Revised (measuring Openness), and the Dementia Rating Scale-2 (measuring global cognitive status and used in validity analyses confirming Information as a CR proxy). Openness accounted for unique variance in Information above and beyond demographics and education, with some evidence of a greater effect at fewer years of education. These results provide preliminary evidence supporting the association between Openness to Experience and CR, a known indicator of resilience to cognitive decline in older adulthood.
\end{abstract}

Keywords: Reserve; Personality; Resilience; Cognitive Decline; Aging; Dementia

Cognitive decline and dementia pose a serious health concern for the aging U.S. population. Alzheimer's Disease (AD) alone affects roughly 2.4 million older Americans and yields health care costs of \$80-100 billion annually [1]. Epidemiologic research has identified demographic and lifestyle factors that are associated with greater resilience to the development of dementing illnesses. For example, research has shown that lower rates of dementia (or behavioral manifestations of dementia) are associated with greater educational attainment $[2,3]$, greater social engagement [4,5], and certain personality characteristics [6-8]. For example, high levels of Neuroticism and low levels of Conscientiousness in middle adulthood have been associated with highly increased risk for developing Alzheimer's disease in late life [9]. However, research has yet to examine the unique and overlapping associations of such factors with cognitive underpinnings of resilience to neurodegenerative disease.

The principal cognitive indicator of relative resilience to the effects of neurodegenerative diseases is Cognitive Reserve (CR), which is associated with less neuropathology in old age, as well as less than expected cognitive impairment when neuropathology does occur $[10,11]$. CR refers to the ability to efficiently use existing neural networks [12] to solve problems, retrieve information, and perform other cognitively-demanding tasks in spite of brain insult. CR has traditionally been viewed as synonymous with one's general fund of knowledge; clear positive relationships between fund of knowledge and resilience to the effects of brain insult over the lifespan have been demonstrated $[13,14]$. Therefore, CR is traditionally estimated by performance on tests of crystallized intelligence, such as reading ability, general knowledge, and vocabulary [13,15]. Importantly, because performance on tests of crystallized intelligence is relatively unaffected by early neurodegenerative changes, it can also be used to estimate a person's life-long (or premorbid) level of CR $[12,16]$. Although CR is apparently determined in part by genetics $[17,18]$, there is evidence to suggest that the neurological basis for CR can also be influenced by environment and lifestyle [19]. In animal models, enriched environments facilitate synapse maturation [20] and increase brain-derived neurotrophic factor, which promotes neurogenesis in areas of the brain important for memory [21]. Importantly, enriched environments also decrease behavioral manifestations of brain lesions [22]. In humans, enriched environments, most commonly operationalized as educational attainment, are also related to $\mathrm{CR}$ [23-25]. For example, educational attainment is highly correlated with general fund of knowledge/crystallized intelligence [16,2628 ], and, as mentioned earlier, educational success is associated with apparent resilience to the development of dementia [2,3]. In addition to educational attainment, personality traits may also play a role in CR development insofar as they contribute to cognitive flexibility [29] and complex mental activity across the lifespan [30]. Specifically, there appear to be reliable associations between Five Factor Model personality traits ${ }^{1}$, indices of CR (e.g., crystallized intelligence), known correlates of CR (e.g., education), and indicators of dementia. For example, low Extraversion and high Openness to Experience (i.e., Openness) are associated with high crystallized intelligence (i.e. CR) [31,32] and academic success [33], and moderate levels of Neuroticism are also associated with higher crystallized intelligence [31] and higher educational attainment [34]. However, some studies have found that Openness is the only personality factor positively correlated with both fluid and crystallized intelligence [35]. Thus, whereas high intelligence and academic success are associated with several personality factors (low Extraversion, moderate Neuroticism, and high Openness), Openness may have a particularly prominent relationship with the development and maintenance of CR.

${ }^{1}$ The Five Factor Model of personality includes Openness to Experience (with higher scores reflecting greater intellectual curiosity and comfort with novel experiences), Conscientiousness (with higher scores reflecting greater efficiency, organization, and achievement striving), Extraversion (with higher scores reflecting an outgoing interpersonal style and high activity level), Agreeableness (with higher scores reflecting greater compassion, cooperation, and conflict avoidance), and Neuroticism (with higher scores reflecting greater propensity to negative affect) [41].

*Corresponding author: Emilie I Franchow, Department of Psychology, University of Utah, 380 S, 1530 E, BEHS 502, Salt Lake City, UT 84112, USA, E-mail: emilie.franchow@psych.utah.edu

Received July 05, 2013; Accepted September 14, 2013; Published September 20, 2013

Citation: Franchow El, Suchy Y, Thorgusen SR, Williams P (2013) More than Education: Openness to Experience Contributes to Cognitive Reserve in Older Adulthood. Aging Sci 1: 109. doi: 10.4172/2329-8847.1000109

Copyright: () 2013 Franchow El, et al. This is an open-access article distributed under the terms of the Creative Commons Attribution License, which permits unrestricted use, distribution, and reproduction in any medium, provided the original author and source are credited. 
Importantly, although the studies outlined above have demonstrated linear and univariate associations between personality, educational attainment, and CR, some studies have begun to examine more complex multivariate and non-linear associations. For example, the association between CR and Openness appears to be moderated by levels of fluid intelligence [36]. Associations between academic performance and Openness appear to be moderated by a number of factors, including academic level (such that high levels of Openness become less related to academic performance in tertiary education) and age (such that the relationship between Openness and academic performance decreases with age) [37]. Additionally, in some studies, Openness does not appear to cotribute to education above and beyond intelligence [38], whereas in others both constructs contribute independently [39]. Taken together, findings suggest complex relationships among correlates of CR, and examination of moderation effects has been recommended [37].

In summary, it appears that both educational attainment and personality characteristics are associated with greater resilience to dementia in the context of underlying neuropathology, possibly via promotion of CR. However, the literature also shows that personality and educational success are themselves related to each other $[33,40,41]$, or may interact with one another in their effect on CR [37]. Consequently, it is unclear whether personality and education contribute independently to $\mathrm{CR}$, whether they interact in their contribution to $\mathrm{CR}$, or whether they represent two measurements of a single underlying contributing factor. The purpose of the current study is to further elucidate the interrelationships among personality, educational attainment, and CR. The current study aims to (1) examine the association between CR (operationalized as crystallized intelligence) and the Five Factor Model personality factors as well as (2) test the hypothesis that personality accounts for variance in CR above and beyond education alone.

\section{Method}

\section{Participants}

Participants ( $\mathrm{n}=72 ; 61 \%$ female) were Caucasian, right-handed, older adults living independently in the community. Participants ranged in age from 60 to 87 years $(M=70.46, S D=6.82)$ with between 10 and 22 years of education $(M=14.65, S D=2.60)$. Education was normally distributed, with a median of 14.0 years and skewness of.519 ( $\mathrm{SE}=.283$ ). Participants' Dementia Rating Scale-Second Edition (DRS2) [42] total raw scores ranged from 117 to $144(\mathrm{M}=137.81, \mathrm{SD}=5.05)$. On the Geriatric Depression Scale (GDS) [43], participants endorsed between 0 and 26 depressive symptoms out of a possible $30(M=5.08$, $\mathrm{SD}=5.20$ ), with the majority of the sample falling in the mild/normal range $(0-9 ; n=64)$. All participants were recruited from the community via advertisements and senior health fairs. Exclusion criteria included left-handedness, diagnosed dementia, moderate/severe chronic illness, and vision, hearing, or motor problems (e.g., paralysis, severe arthritis, etc.) that would preclude participants from completing surveys or tasks requiring motor control.

\section{Procedure}

After an initial telephone screening, participants were scheduled for testing in the researchers' lab space in the Department of Psychology at the University of Utah. Participants underwent standard IRB-approved informed consent procedures. As part of a larger study, participants were administered a battery of cognitive and psychological measures by trained study personnel, who were unfamiliar with hypotheses associated with this portion of the larger study. The entire session lasted approximately 3 hours. Participants were reimbursed at the rate of $\$ 30$ per session and were provided brief feedback regarding the results of cognitive and depression screening measures. All procedures were in compliance with institutional standards for research with human participants (in compliance with the University of Utah IRB).

\section{Measures}

Personality: All participants completed the NEO Personality Inventory-Revised (NEO PI-R), a 240-item self-report measure designed to assess the domains of the Five Factor Model of personality. The NEO PI-R includes higher order factors (i.e., Neuroticism, Extraversion, Openness, Agreeableness, and Conscientiousness) that have been demonstrated to have high internal consistency, convergent and discriminate validity and reliabilities ranging from.86 to.91 [41].

Cognitive Reserve: Participants completed the Wechsler Adult Intelligence Scale-Third Edition (WAIS-III) [44] Information subtest, a measure of crystallized intelligence that is considered an appropriate proxy for CR [45]. Information has long been known as a highly reliable estimate of premorbid intelligence $[46,47]$, is strongly related to years of education [48], and is highly correlated with the WAIS Vocabulary subtest, another measure of pre-morbid intellectual functioning that has been used as a proxy measure of CR in previous studies [49,50] while featuring a shorter administration time. Reported reliabilities are excellent, ranging from. 93 to. 95 for ages 55 to 89 in the normative sample [44]. Because Information measures crystallized intelligence, it tends to be relatively unaffected by many types of neurological damage [51-53].

Mood and General Cognition: As a means of characterizing the sample, participants completed the Geriatric Depression Scale (GDS) [43] which is a self-report screening measure of depression, and the Dementia Rating Scale Second Edition (DRS-2) [42], which is a screening measure of dementia. In contrast to Information, the DRS-2 measures those aspects of cognition that are prone to decline with old age or as a result of neuropathology.

\section{Results}

\section{Preliminary Analyses}

Zero order correlations and validity check: Zero order correlations were used to examine the relationships between the five personality factors, educational attainment, and crystallized intelligence (see Table 1). As expected, Openness (including 4 of its 6 facets) was significantly correlated with both educational attainment $(r=.459)$ and Information scores $(r=.405)$. Openness and Agreeableness were also significantly associated with younger age ( $r=-.268 ; r=-.254)$. However, the remaining personality factors were not related to either education or Information scores (despite a similar range of normally-distributed scores observed on all personality factors in this sample; see Table 1 for sex-corrected $\mathrm{T}$ scores). Additionally, as expected, Education and Information scores were significantly correlated with each other $(r=.530)$. Lastly, as expected, age was significantly correlated with current cognitive status, as assessed via the DRS-2 ( $r=-.391)$, but not with Information scores or levels of education. The association of age with the DRS-2 scores is to be expected, due to the known increases in brain neuropathology with increasing age [54] (Table 1).

Next, as a validity check, we wanted to determine whether Information scores served as a valid measure of CR in this sample. To that end, we divided the group based on a median split of Information raw scores and examined the association between age and DRS-2 scores in both groups. Recall that whereas Information scores tend to 
Citation: Franchow El, Suchy Y, Thorgusen SR, Williams P (2013) More than Education: Openness to Experience Contributes to Cognitive Reserve in Older Adulthood. Aging Sci 1: 109. doi: 10.4172/2329-8847.1000109

Page 3 of 8

\begin{tabular}{|c|c|c|c|c|c|c|}
\hline & r Education & r Cognitive Reserve & $\begin{array}{c}r \\
\text { Age }\end{array}$ & Mean & Standard Deviation & Range \\
\hline Openness & $.459^{* *}$ & $.405^{\star *}$ & $-.268^{*}$ & 50.56 & 11.04 & $28-77$ \\
\hline Fantasy & $.297^{*}$ & $.280^{*}$ & -.198 & & & \\
\hline Aesthetics & $.361^{* *}$ & $.344^{* *}$ & -.115 & & & \\
\hline Feelings & $.343^{* *}$ & .208 & $-.290^{*}$ & & & \\
\hline Actions & $.241^{*}$ & .152 & -.173 & & & \\
\hline Ideas & $.377^{* *}$ & $.422^{* *}$ & -.105 & & & \\
\hline Values & $.298^{*}$ & $.259^{*}$ & $-.258^{*}$ & & & \\
\hline Conscientiousness & .005 & .064 & -.053 & 45.29 & 11.10 & $20-72$ \\
\hline Extraversion & .080 & .008 & -.099 & 47.97 & 9.33 & $25-72$ \\
\hline Agreeableness & -.128 & -.127 & $-.254^{*}$ & 49.14 & 9.50 & $26-70$ \\
\hline Neuroticism & -.068 & -.045 & .042 & 49.92 & 10.55 & $29-80$ \\
\hline
\end{tabular}

Note. $r=$ Pearson's r; Education= years of education completed; Cognitive Reserve= total raw Information score; Openness= NEO-PI-R Openness subscale T score; Fantasy, Aesthetics, Feelings, Actions, Ideas, Values= facets of the Openness subscale; Conscientiousness= NEO-PI-R Conscientiousness subscale $T$ score; Extraversion= NEOPI-R Extraversion subscale T score; Agreeableness= NEO-PI-R Agreeableness subscale T score; Neuroticism= NEO-PI-R Neuroticism subscale T score. ${ }^{*} p \geq .05$, "* $p \geq .01$. Table 1: Zero-Order Correlations and Descriptive Statistics for the NEO-PI-R Factors.

\begin{tabular}{|c|c|c|c|c|c|c|c|}
\hline Step & Predictor & $\mathrm{R}^{2}$ & Adjusted $\mathrm{R}^{2}$ & $\mathrm{R}^{2} \Delta$ & $\mathrm{F} \Delta$ & df & $p$ value \\
\hline \multicolumn{8}{|c|}{ Model 1} \\
\hline 1 & Age, Gender & .124 & .098 & .124 & 4.877 & 2,69 & .010 \\
\hline 2 & Education & .329 & .299 & .299 & 20.747 & 1,68 & .000 \\
\hline 3 & Openness & .401 & .365 & .072 & 8.102 & 1,67 & .006 \\
\hline \multicolumn{8}{|c|}{ Model 2} \\
\hline 2 & Openness & .332 & .302 & .208 & 21.165 & 1,68 & .000 \\
\hline 3 & Education & .401 & .365 & .069 & 7.751 & 1,67 & .007 \\
\hline 4 & $\mathrm{O} \times \mathrm{E}$ & .415 & .371 & .014 & 1.609 & 1,66 & .209 \\
\hline
\end{tabular}

Note. Italicized numbers in the $\mathrm{R}^{2} \Delta$ column reflect unique variance contributions; Step 1 values for $\mathrm{F} \Delta$ represent $\mathrm{F}$, as they are the values for the base model; Education= years of education completed; Openness=NEO-PI-R Openness subscale raw score; $\mathrm{O}$ x E=product of Openness and Education (i.e., the interaction term).

Table 2: Summary of Hierarchical Regressions: Contributions of Demographics, Openness, and the Interaction Between Education and Openness to a Measure of Crystallized Intelligence.

be relatively unaffected by many types of neurological damage [51-53], the DRS-2 test is, by design, highly sensitive to detecting early cognitive decline secondary to neurodegenerative processes [42,55,56]. We reasoned that if Information scores served as a valid measure of $\mathrm{CR}$ in this sample, then individuals with better Information performance should show a smaller effect of age on their DRS-2 scores. This was in fact the case. In examining the relationship between age and the DRS-2 scores, we plotted regression lines for individuals in the low and the high Information groups separately. Consistent with prior research showing a nonlinear relationship between age and cognitive decline (such that rates of decline increase with age) [57-60], we applied a quadratic model to the relationship between DRS-2 performance and age. Consistent with expectation, only the low Information group (indicating low CR) showed a significant association between age and the DRS-2 scores $[F(2,38)=14.51, p<.001]$, with age accounting for $43.3 \%$ of variance in cognitive status. In contrast, age accounted for non-significant variance in cognitive status (11.1\%) among the high Information (i.e., high CR) group. These analyses confirmed the validity of Information scores as a proxy for CR in this sample.

\section{Principal analyses}

Unpacking the Associations between CR, Education, and Openness: To examine whether personality and educational attainment represent unique or overlapping predictors of $\mathrm{CR}$, we conducted a series of hierarchical regressions using Information raw score as the criterion variable. Age and gender were entered as predictors on Step 1 to control for demographic factors related to crystallized intelligence. Next, we entered educational attainment (in years) and Openness raw scores on Steps 2 and 3, respectively. In a separate analysis, we reversed Steps 2 and 3 in order to determine the amount of unique and overlapping variance accounted for by Openness and education. Summaries of analyses are presented in Steps 1 through 3 in Table 2, with the italicized numbers in the $\mathrm{R}^{2} \Delta$ column reflecting unique variance contributed by each variable. As can be seen in the Table, Openness and education together accounted for $27.7 \%$ of variance above and beyond age and gender (i.e., total variance, or.401, minus the age and gender variance, or.124). Importantly, whereas $13.6 \%$ of the variance accounted for was shared between Openness and education (i.e.,.277 minus the sum of the unique variances, or the italicized numbers in the $\mathrm{R}^{2} \Delta$ column), the table shows that $7.2 \%$ and $6.9 \%$ of the variance represented unique, non-overlapping contributions by Openness and education, respectively. In a non-hierarchical linear regression model, Openness $(b=.072, \mathrm{t}=2.846, p<.05)$ and education $(b=.533, \mathrm{t}=2.784, p<.05)$ also each contributed significantly to the model $(F[4,67]=11.218, p<.001)$, consistent with their unique contributions.

Interaction between Openness and Education: Lastly, as recommended by Poropat [37], we examined the possibility that an interaction between education and Openness also contributed to the model. We repeated the above analyses, adding the interaction terms on Step 4 (see Table 2, Step 4). Results showed that the interaction term did not contribute significantly above and beyond the other variables. However, in an exploratory examination of simple effects, we also 


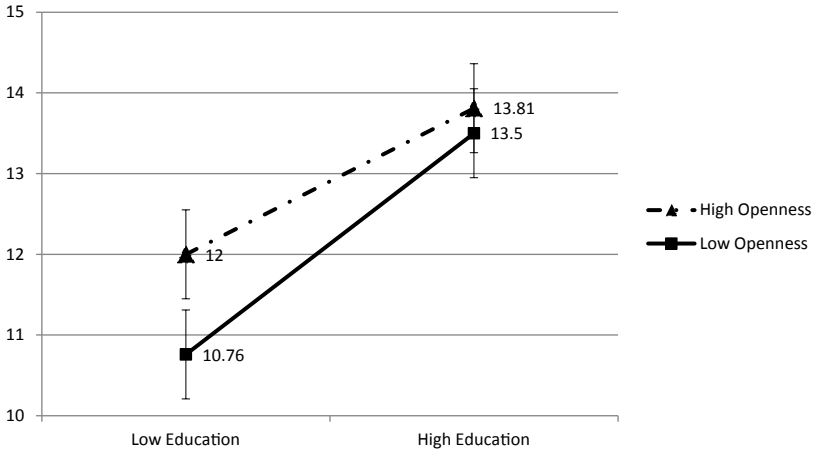

Figure 1: Information scaled scores for individuals with low and high levels of openness and education. Scaled scores reflect how raw Information scores compare to a normative sample (based on test manual), such that normative sample mean is 10 and standard deviation is 13 . Groups were created by median split; High education $\geq 3$ years of college completed; Low education $<3$ years of college completed; High openness > 112 (raw score); Low Openness $<112$ (raw score). Standard errors are represented in the figure by error bars attached to each data point.

conducted a series of simple slope analyses. The regression model was restructured on high and low values (one standard deviation above and below the mean) of education [61]. In these analyses, Openness was significantly associated with $\mathrm{CR}$ at low $(b=.072, \mathrm{t}=2.867, p=.006)$ levels of education. However, the association was non-significant at high $(b=.044, \mathrm{t}=1.293, p=.20)$ and average $(\mathrm{b}=.229, \mathrm{t}=1.815, p=.074)$ levels of education. These results suggest that Openness might play an increasingly independent role in building CR at lower levels of formal education. Findings are illustrated in Figure 1 (mean Information scaled scores for individuals with low versus high education, divided into high versus low Openness groups). Because educational attainment was normally distributed (see above) and the mean level of education in this sample was comparable to that in large samples of older adults in recent aging research $[62,63]$, the sample was divided into high and low education groups based on a median split to illustrate the results of our simple slope analyses (Figure 1).

In sum, the present findings indicate an association between Openness and CR (i.e., crystallized intelligence), with Openness contributing to crystallized intelligence beyond education and demographic factors alone. Although the interaction between Openness and education did not reach significance in the current sample, simple slope analyses suggested that Openness may be more significantly associated with CR among individuals with fewer years of education.

\section{Discussion}

\section{Key findings}

The present study investigated links between cognitive reserve (CR; operationalized as crystallized intelligence, assessed via the Information subtest of the WAIS-III) and Five Factor Model personality traits in a sample of community-dwelling older adults. Key findings are that (a) Openness was positively correlated with $\mathrm{CR}$ and accounted for variance in CR above and beyond educational attainment, and (b) the relationship between Openness and CR may differ based on level of education, such that Openness plays a more central role in CR among individuals completing fewer years of education. No associations were found between education or Information scores and Conscientiousness, Extraversion, Agreeableness, or Neuroticism.

\section{Theoretical Implications}

Shared variance among Openness, education and CR: Consistent with previous research, these results demonstrate a positive correlation between Openness and education. This relationship could be explained by a tendency for individuals high on Openness to pursue higher education [64]. Or, it might be the case that higher education is Openness-promoting, fostering high levels of intellectual engagement and curiosity [65]. Individuals with high educational attainment are exposed to broader cultural, economic, and geographic diversity, both via classroom instruction and subsequent occupational pursuits. This increased exposure likely promotes increased openness to diverse experiences, and undoubtedly contributes to life-long knowledge acquisition (i.e., CR). Consequently, the reciprocal relationship between Openness and education is likely reflected in the variance that the three variables (i.e., Openness, CR, and education) share in common. A potential interaction between Openness and education would suggest that the CR-promoting properties of these two factors are at least partially reflective of a single, underlying effect of engagement with the world.

Unique contribution of Openness and education to CR: These results also show that education and Openness each uniquely contribute to CR. For those completing more years of education, formal schooling may be the predominant pathway toward the accumulation of knowledge. Although, as stated above, these individuals tend to be higher on Openness in general, Openness may be unnecessary for their knowledge to be well developed. As illustrated in Figure 1, individuals who completed more years of education exhibited above average crystallized intelligence (i.e., scaled scores between 13 and 14, more than 1 S.D. above the normative sample), regardless of their level of Openness.

On the other hand, for those completing fewer years of education, Openness may be an important factor in the development of CR. As Figure 1 shows, less-educated individuals who were also low on Openness exhibited approximately average crystallized knowledge (i.e., scaled score $=10.76$ ), whereas those who were more Open exhibited crystallized knowledge in the high average range (i.e., scaled score $=12$, or $2 / 3$ S.D. above the normative sample). In other words, although individuals completing fewer years of formal education in this sample tended to be lower on Openness in general, those who were more Open tended to accumulate greater $\mathrm{CR}$ than their similarly-educated but lessOpen peers. This suggests that high Openness may be associated less with formal schooling and more with intellectual curiosity, preference for new experiences, and a broad range of interests in this group [66]. Therefore, Openness likely builds crystallized knowledge beyond the classroom via exposure to new people, places, and situations. Interestingly, most people in the high Openness/lower education group were women $(84.6 \%)$; some of these women may have been college-bound and interrupted studies to have families. Alternatively, as suggested by Poropat [37], it may be the case that personality is a somewhat less-important contributor to academic success (and development of CR) in post-secondary education. Because most primary and secondary education is structured in a relatively standard way, individual differences contributing to success (including high levels of Openness) may be more obvious in this setting. However, in college and beyond, students make more individualized choices about programs of study and other aspects of learning environment that may mask the effect of underlying individual differences in trait Openness and other personality characteristics. 
However, empirical support for these proposed mechanisms is currently lacking, and the interaction between education and Openness predicting CR did not reach significance in this sample. Occupation, socioeconomic status, and level of engagement in knowledge-enhancing activities (e.g. reading, games, travel, etc.) may modify the relationship between trait levels of Openness and crystallized intelligence. Future studies should examine these variables in order to pinpoint the mechanisms by which personality influences cognitive reserve. The present results provide some indication of a particular association between Openness and CR for individuals who have completed fewer years of formal education based on apparent differences in CR between less and more Open individuals among those completing fewer years of education. However, these are based on exploratory analyses; a continuous interaction between Openness and education did not significantly contribute to CR in this sample.

Openness as a buffer against dementia: The above-described mechanisms offer an explanation of how Openness may contribute to $\mathrm{CR}$, which in turn is thought to delay cognitive decline in individuals who exhibit neurodegenerative changes in the brain. However, diagnostic criteria for dementia require both a decline in cognition and a decline in daily functioning. We recently reported that Openness is associated with better ability to engage in instrumental activities of daily living [8]. This may mean that the experience-seeking component of Openness [66] builds a procedural aspect of reserve by increasing comfort with novel situations and creating a large array of templates on which to build responses to new problems.

Lastly, Openness is defined not only by engagement with the world, but also by willingness to explore one's internal states [66]. Thus, highlyOpen individuals may be more willing to face their own cognitive or functional difficulties and more willing to adopt novel compensatory strategies. This notion is consistent with research showing that higher education is associated with greater cognitive complaints prior to the onset of dementia [67], suggesting earlier insight into cognitive change. Similarly, we have recently found that higher crystallized intelligence is also associated with better insight into functional limitations [8]. Given that Openness is associated with cognitive flexibility [35], it likely increases the probability that a person will respond flexibly (with new strategies) both before and after experiencing cognitive and functional decline. In sum, it appears that lower levels of dementia seen in individuals high in Openness [6] may on the one hand reflect a more versatile set of templates utilized for daily functionality, and on the other a greater self-knowledge and flexibility relevant to recognizing and adapting to cognitive decline.

\section{Negative Findings}

The lack of association between education, CR, and any other personality factor in this sample is somewhat inconsistent with previous research. Although some research has demonstrated that moderate Neuroticism, low Extraversion, and high Conscientiousness are associated with higher crystallized intelligence and with academic success [31-34,37], these traits were unrelated to education or Information scores in the current study. However, given that other studies have found either an exclusive relationship between Openness and crystallized intelligence [35] or smaller effect sizes for the relationships between the other four traits and crystallized intelligence [32], a larger sample may be needed for all possible relationships to reach significance (see Table 1). However, it should be noted that average $\mathrm{T}$ scores for all five personality factors in this sample were normally-distributed and similar to those observed in the Baltimore Longitudinal Study of Aging, which examined age-related trends in the
NEO-PI factors in a large sample of older adults [63]. This indicates that our negative findings were likely not due to a restricted range or skewed distribution of personality factors in this sample. Additionally, previous studies relied either on a younger sample [31] or a wider age range $[32,33]$. Because some change is observed in relationships between personality factors and crystallized intelligence across the lifespan [32], the older age of our sample might have contributed to the null findings for other personality factors.

The interaction between Openness and education was also non-significant in this sample. It is possible that these analyses were underpowered in a sample of this size, or that a potential moderating effect between Openness and educational attainment is incomplete without taking additional demographic, socioeconomic, and other lifestyle factors into account. However, because recent research supports examining possible moderation effects of level of education on the relationship between personality traits and academic success (a contributor to CR) [37], exploratory analyses of a potential interaction are included in this study. Although the simple slopes analyses should be interpreted with caution, they provide preliminary support for a differentially significant role of Openness with fewer years of education completed. The potential interaction between Openness and education should be examined in future studies with a larger sample and inclusion of demographic, socioeconomic, and other lifestyle factors to further characterize the complex relationships among contributing factors to CR.

\section{Implications for Future Research}

As the personal and public health toll of neurodegenerative diseases continues to rise [1], it is important to determine the degree to which cognitive and personality factors are associated with risk for the development of dementia. These results suggest that in addition to the known protective factor of higher education, Openness may also be associated with CR in late life. While associations between personality factors and both educational attainment and crystalized intelligence have been established, a direct link between personality traits and resilience to neurodegeneration has been largely overlooked in the cognitive aging literature. These results support the utility of including measures of personality in future research on the nature of CR. Additionally, to the extent that Openness represents an engaged lifestyle, researchers may also wish to consider other methods of measuring level of engagement with new knowledge and experiences across the lifespan other than level of formal education as well as how this engagement confers cognitive benefit in old age. Future research should also focus on incorporating known correlates of CR into the development of screening measures to identify adults at risk for cognitive decline. Additionally, future research should employ longitudinal designs to examine the utility of CR correlates in predicting the approximate age of onset of cognitive decline among individuals with an early diagnosis of a neurodegenerative process.

\section{Crystallized intelligence as a measure of $\mathrm{CR}$}

The present study builds on the assumption that crystallized intelligence (assessed via general knowledge) can serve as an index of CR [45]. Tests of word knowledge (i.e., crystallized intelligence) are widely-used measures of CR [68,69], and some studies show a relationship between these traditional CR indices and measures of neural reserve [70]. Nevertheless, the association between biological and cognitive indices of reserve has been under-studied [71], calling for systematic examination of the validity of such indices [30]. The neural reserve construct explains resilience to neuropathology in 
more direct neurobiological terms: by the flexibility of neural systems underlying cognitive abilities [72] as measured by synaptic connectivity [73], neural network complexity [74], neural efficiency [45], and premorbid brain volume $[75,76]$. However, neural reserve and CR are by no means incompatible, and may reflect differing measurements of the same underlying construct (i.e. the strength/flexibility of neural networks and cognitive abilities and their corresponding resilience to neuropathology) [30].

In the present study, we conducted a validity check, examining whether higher Information scores are in fact associated with less age-related decline in cognition. Our findings showed that whereas individuals with high Information scores were relatively unaffected by age in terms of their general neurocognitive status assessed by the DRS-2, those with low Information scores showed expected age-related decline. This is consistent with literature supporting links between higher intelligence [17], higher education [77], and delayed onset and/or progression of cognitive decline in dementia. However, we are unaware of any research providing support for the specific association shown here between higher crystallized intelligence and relative stability on a measure of global cognitive ability with age. Future studies using measures of crystallized intelligence as a proxy for CR should conduct validity checks and add to the sparse existing literature on their utility in measuring protection against cognitive decline.

\section{Limitations}

The present study has several limitations. First, it examined a relatively modest sample $(\mathrm{n}=72)$ of older adults. Although there is some evidence to support the resilience of personality [78] and WAIS verbal performance (i.e. crystallized intelligence) [79] to neurologic injury, there is also evidence supporting changes in both domains post-injury $[80,81]$. Future studies should systematically examine the relationships between Openness, education, and crystallized intelligence in neurologic populations. Additionally, the sample was highly educated and included only Caucasians. Consequently, these results need to be replicated in a larger, demographically-diverse sample before they can be reliably applied to the general population of older adults.

Second, we relied on a single measure of CR (Information raw scores), operationally defining CR as crystallized intelligence. Recent research emphasizes the importance of multiple indicators for the validation of the reserve construct [30], and at the level of the individual case, it is well understood that reliability is improved by combining multiple measures (e.g. including Vocabulary or Similarities subtests from the WAIS-III). Nevertheless, validity analyses in this sample support the utility of Information as a stable measure of crystallized abilities (as opposed to DRS-2 scores, which showed a significant negative relationship with age). In addition, the known reliability of the Information subtest is quite high (.93 -.95 for the age groups included in this sample) [40]. Future studies should also examine the universal utility of crystallized intelligence as an index of CR. Indeed, recent research calls for the investigation of multiple possible factors underlying the CR construct (e.g. general intelligence, complex mental activity, processing resources, and executive functions [30], some of which are more closely related to crystallized intelligence than others. While crystallized intelligence is generally considered an appropriate proxy for CR [41], interaction effects may be present based on level of education. Perhaps crystallized intelligence captures CR well in highly educated individuals, but does not serve as an ideal index of CR among those who have completed fewer years of formal education.

Finally, we relied on a single self-report measure of personality.
The use of informant reports or additional personality measures may have offered additional information about the relationships between personality, education, and CR. For instance, Duchek et al. [7] found that informant reports of increased Neuroticism and decreased Conscientiousness on the NEO Five Factor Inventory [41] were sensitive to differences between healthy controls and early-stage DAT. However, they also noted good agreement between self-report and informant ratings across all five personality traits [7], suggesting that informant reports may offer relatively small incremental utility above and beyond both self-reports and cognitive testing in categorizing participants into healthy control and early dementia groups.

\section{Acknowledgments}

The authors would like to acknowledge the contribution of Matt Kraybill, who was the primary investigator during data collection and responsible for project management and recruitment of participants. We would also like to acknowledge Kaycie Maureen Kuss for her assistance with data collection. Emilie Franchow, Yana Suchy, Sommer Thorgusen, and Paula Williams were responsible for the conception of the research idea for this paper, data analysis, and writing of the manuscript. The authors have no financial or any other kind of personal conflicts with this manuscript. This research received no specific grant from any funding agency, commercial or not-for-profit sectors. Portions of this paper were presented as an abstract at the meeting of the International Neuropsychological Society (2011).

\section{References}

1. Attix DK, Welsh-Bohmer KA (2006) Geriatric neuropsychology: Assessment and intervention. New York, NY US: Guilford Publications.

2. McDowell I, Xi G, Lindsay J, Tierney M (2007) Mapping the connections between education and dementia. J Clin Exp Neuropsychol 29: 127-141.

3. Qiu C, Xu W, Fratiglioni L (2010) Vascular and psychosocial factors in Alzheimer's disease: epidemiological evidence toward intervention. J Alzheimers Dis 20: 689-697.

4. Fratiglioni L, Paillard-Borg S, Winblad B (2004) An active and socially integrated lifestyle in late life might protect against dementia. Lancet Neurol 3: 343-353.

5. Saczynski JS, Pfeifer LA, Masaki K, Korf ES, Laurin D, et al. (2005) The effect of social engagement on incident dementia: the Honolulu-Asia Aging Study. Am J Epidemiol 163: 433-440.

6. Duberstein PR, Chapman BP, Tindle HA, Sink KM, Bamonti P, et al. (2011) Personality and risk for Alzheimer's disease in adults 72 years of age and older: a 6-year follow-up. Psychol Aging 26: 351-362.

7. Duchek JM, Balota DA, Storandt M, Larsen R (2007) The power of personality in discriminating between healthy aging and early-stage Alzheimer's disease. J Gerontol B Psychol Sci Soc Sci 62: P353-361.

8. Suchy Y, Williams PG, Kraybill ML, Franchow E, Butner J (2010) Instrumental activities of daily living among community-dwelling older adults: Personality associations with self-report, performance, and awareness of functional difficulties. J Gerontol B Psychol Sci Soc Sci 65: 542-550.

9. Terracciano A, Sutin AR, An Y, O’Brien RJ, Ferrucci L, et al. (2013) Personality and risk of Alzheimer's disease: New data and meta-analysis. Alzheimers Dement

10. Staff RT, Murray AD, Deary IJ, Whalley LJ (2004) What provides cerebral reserve? Brain 127: 1191-1199.

11. Scheltens P, Rockwood K (2011) How golden is the gold standard of neuropathology in dementia? Alzheimers Dement 7: 486-489.

12. Stern Y (2007) Cognitive reserve: Theory and applications. Philadelphia, PA US: Taylor \& Francis.

13. Sumowski JF, Wylie GR, DeLuca J, Chiaravalloti N (2010) Intellectual enrichment is linked to cerebral efficiency in multiple sclerosis: Functional magnetic resonance imaging evidence for cognitive reserve. Brain: A Journal of Neurology 133: 362-374.

14. Tucker-Drob EM, Johnson KE, Jones RN (2009) The cognitive reserve hypothesis: a longitudinal examination of age-associated declines in reasoning and processing speed. Dev Psychol 45: 431-446.

15. Cattell RB (1971) Abilities: their structure, growth, and action. Oxford England Houghton Mifflin 
Citation: Franchow El, Suchy Y, Thorgusen SR, Williams P (2013) More than Education: Openness to Experience Contributes to Cognitive Reserve in Older Adulthood. Aging Sci 1: 109. doi: 10.4172/2329-8847.1000109

16. Sachdev PS, Valenzuela M (2009) Brain and cognitive reserve. Am J Geriatr Psychiatry 17: 175-178

17. Bracco L, Piccini C, Baccini M, Bessi V, Biancucci F, et al. (2007) Pattern and progression of cognitive decline in Alzheimer's disease: role of premorbid intelligence and ApoE genotype. Dement Geriatr Cogn Disord 24: 483-491.

18. Lee JH (2003) Genetic evidence for cognitive reserve: variations in memory and related cognitive functions. J Clin Exp Neuropsychol 25: 594-613.

19. Scarmeas N, Stern $Y(2003)$ Cognitive reserve and lifestyle. J Clin Exp Neuropsychol 25: 625-633.

20. He S, Ma J, Liu N, Yu X (2010) Early enriched environment promotes neonata GABAergic neurotransmission and accelerates synapse maturation. J Neurosci 30: 7910-7916

21. Kuzumaki N, Ikegami D, Tamura R, Hareyama N, Imai S, et al. (2011) Hippocampal epigenetic modification at the brain-derived neurotrophic facto gene induced by an enriched environment. Hippocampus 21: 127-132.

22. Mandolesi L, De Bartolo P, Foti F, Gelfo F, Federico F, et al. (2008) Environmental enrichment provides a cognitive reserve to be spent in the case of brain lesion. J Alzheimers Dis 15: 11-28.

23. Bickel H, Kurz A (2009) Education, occupation, and dementia: the Bavarian school sisters study. Dement Geriatr Cogn Disord 27: 548-556.

24. Petrosini L, De Bartolo P, Foti F, Gelfo F, Cutuli D, et al. (2009) On whether the environmental enrichment may provide cognitive and brain reserves. Brain Res Rev 61: 221-239.

25. Richards M, Sacker A, Deary IJ (2007) Lifetime antecedents of cognitive reserve.

26. Leli DA, Filskov SB (1979) Relationship of intelligence to education and occupation as signs of intellectual deterioration. J Consult Clin Psychol 47: 702-707.

27. Matarazzo JD, Herman DO (1984) Relationship of education and IQ in the WAIS-R standardization sample. Journal of Consulting and Clinical Psychology 52: 631-634.

28. Tambs K, Sundet JM, Magnus P, Berg K (1989) Genetic and environmental contributions to the covariance between occupational status, educational attainment, and IQ: a study of twins. Behav Genet 19: 209-222.

29. Sutin AR, Terracciano A, Kitner-Triolo MH, Uda M, Schlessinger D, et al. (2011) Personality traits prospectively predict verbal fluency in a lifespan sample. Psychol Aging 26: 994-999.

30. Satz P, Cole MA, Hardy DJ, Rassovsky Y (2011) Brain and cognitive reserve: mediator(s) and construct validity, a critique. J Clin Exp Neuropsychol 33: 121 130.

31. Schretlen DJ, van der Hulst EJ, Pearlson GD, Gordon B (2010) A neuropsychological study of personality: trait openness in relation to intelligence, fluency, and executive functioning. J Clin Exp Neuropsychol 32: 1068-1073.

32. Soubelet A, Salthouse TA (2011) Personality-cognition relations across adulthood. Dev Psychol 47: 303-310.

33. Van Eijck K, De Graaf PM (2004) The Big Five at school: The impact of personality on educational attainment. Netherlands' Journal of Social Sciences 40: $24-40$

34. Sharp ES, Reynolds CA, Pedersen NL, Gatz M (2010) Cognitive engagement and cognitive aging: is openness protective? Psychol Aging 25: 60-73.

35. DeYoung CG, Peterson JB, Higgins DM (2005) Sources of openness/intellect: cognitive and neuropsychological correlates of the fifth factor of personality. $J$ Pers 73: 825-858.

36. Ziegler M, Danay E, Heene M, Asendorpf J, Bühner M (2012) Openness, fluid intelligence, and crystallized intelligence: Toward an integrative model. Journa of Research in Personality 46: 173-183.

37. Poropat AE (2009) A meta-analysis of the five-factor model of personality and academic performance. Psychol Bull 135: 322-338.

38. Furnham A, Monsen J, Ahmetoglu G (2009) Typical intellectual engagement Big Five personality traits, approaches to learning and cognitive ability predictors of academic performance. Br J Educ Psychol 79: 769-782.

39. Ljubica Marjanovic, U, Socan G, Bajc K (2007) Vpliv psiholoških dejavnikov in izobrazbe staršev na ucno uspešnost mladostnikov. Psihološka Obzorja Horizons of Psychology 16: 27-48.

40. Busato VV, Prins FJ, Elshout JJ, Hamaker C (2000) Intellectual ability learning style, personality, achievement motivation and academic success of psychology students in higher education. Personality and Individual Differences 29: 1057-1068.

41. Costa PT, McCrae RR (1992) Manual for the Revised NEO Personality Inventory (NEO-PI-R) and NEO Five-Factor Inventory (NEO-FFI).

42. Jurica PJ, Leitten CL, Mattis S (2001) DRS-2: Dementia Rating Scale-2, Professional Manual.

43. Yesavage JA (1988) Geriatric Depression Scale. Psychopharmacol Bull 24 709-711.

44. PsyCor. (1997). WAIS-III \&WMS-II1Technical Manual.

45. Stern $Y$ (2002) What is cognitive reserve? Theory and research application of the reserve concept. J Int Neuropsychol Soc 8: 448-460.

46. Feingold A (1982) The validity of the Information and Vocabulary subtests of the WAIS. Journal of Clinical Psychology 38: 169-174

47. Bilder RM, Degreef G, Pandurangi AK, Rieder RO, Sackeim HA, et al (1988) Neuropsychological deterioration and CT scan findings in chronic schizophrenia. Schizophr Res 1: 37-45.

48. Malec JF, Ivnik RJ, Smith GE, Tangalos EG, Petersen RC, et al. (1992) Mayo's Older Americans Normative Studies: Utility of corrections for age and education for the WAIS-R. Clinical Neuropsychologist 6: 31-47.

49. Corral M, Rodríguez M, Amenedo E, Sánchez JL, Díaz F (2006) Cognitive reserve, age, and neuropsychological performance in healthy participants. Dev Neuropsychol 29: 479-491.

50. Stern Y, Habeck C, Moeller J, Scarmeas N, Anderson KE, et al. (2005) Brain networks associated with cognitive reserve in healthy young and old adults. Cereb Cortex 15: 394-402.

51. Langeluddecke PM, Lucas SK (2003) Wechsler Adult Intelligence ScaleThird Edition findings in relation to severity of brain injury in litigants. Clin Neuropsychol 17: 273-284.

52. Troster Al, Fields JA, Paolo AM, Koller WC (1996) Performance of individuals with Parkinson's disease on the vocabulary and information subtests of the WAIS-R as a neuropsychological instrument. Journal of Clinical Geropsychology 23: $215-223$.

53. Zhu J, Tulsky DS, Price L, Chen HY (2001) WAIS-III reliability data for clinical groups. J Int Neuropsychol Soc 7: 862-866.

54. O’Brien RJ, Resnick SM, Zonderman AB, Ferrucci L, Crain BJ, et al. (2009) Neuropathologic studies of the Baltimore Longitudinal Study of Aging (BLSA). J Alzheimers Dis 18: 665-675.

55. Matteau E, Dupré N, Langlois M, Jean L, Thivierge S, et al. (2011) Mattis Dementia Rating Scale 2: screening for $\mathrm{MCl}$ and dementia. Am J Alzheimers Dis Other Demen 26: 389-398.

56. Monsch AU, Bondi MW, Salmon DP, Butters N, Thal LJ, et al. (1995) Clinica validity of the Mattis Dementia Rating Scale in detecting Dementia of the Alzheimer type. A double cross-validation and application to a communitydwelling sample. Arch Neurol 52: 899-904.

57. Giambra LM, Arenberg D, Kawas C, Zonderman AB, Costa PT Jr (1995) Adult life span changes in immediate visual memory and verbal intelligence. Psychol Aging 10: 123-139.

58. Kaufman AS, Horn JL (1996) Age changes on tests of fluid and crystallized ability for women and men on the Kaufman Adolescent and Adult Intelligence Test (KAIT) at ages 17-94 years. Arch Clin Neuropsychol 11: 97-121.

59. Park DC, Lautenschlager G, Hedden T, Davidson NS, Smith AD, et al. (2002) Models of visuospatial and verbal memory across the adult life span. Psychol Aging 17: 299-320.

60. Wilson RS, Beckett LA, Barnes LL, Schneider JA, Bach J, et al. (2002) Individual differences in rates of change in cognitive abilities of older persons. Psychol Aging 17: 179-193.

61. Cohen J, Cohen P, West SG, Aiken LS (2003) Applied multiple regression/ correlation analysis for the behavioral sciences (3rd edn).

62. Norton MC, Dew J, Smith H, Fauth E, Piercy KW, et al. (2012) Lifestyle behavior 
Citation: Franchow El, Suchy Y, Thorgusen SR, Williams P (2013) More than Education: Openness to Experience Contributes to Cognitive Reserve in Older Adulthood. Aging Sci 1: 109. doi: 10.4172/2329-8847.1000109

pattern is associated with different levels of risk for incident dementia and Alzheimer's disease: the Cache County study. J Am Geriatr Soc 60: 405-412.

63. Terracciano A, McCrae RR, Brant LJ, Costa PT Jr (2005) Hierarchical linear modeling analyses of the NEO-PI-R scales in the Baltimore Longitudinal Study of Aging. Psychol Aging 20: 493-506.

64. Scepansky JA, Bjornsen CA (2003) Educational, orientation, Neo PI-R personality traits, and plans for graduate school. College Student Journal 37: 574-581.

65. Arteche A, Chamorro-Premuzic T, Ackerman P, Furnham A (2009) Typical intellectual engagement as a byproduct of openness, learning approaches, and self assessed intelligence. Educational Psychology 29: 357-367.

66. McCrae RR, Costa PT Jr (1997) Conceptions and correlates of openness to experience. In Hogan R, Johnson JA \& Briggs SR (Eds), Handbook of personality psychology. (pp. 825-847). San Diego, CA US: Academic Press.

67. van Oijen M, de Jong FJ, Hofman A, Koudstaal PJ, Breteler MM (2007) Subjective memory complaints, education, and risk of Alzheimer's disease. Alzheimers Dement 3: 92-97.

68. Alexander GE, Furey ML, Grady CL, Pietrini P, Brady DR, et al. (1997) Association of premorbid intellectual function with cerebral metabolism in Alzheimer's disease: implications for the cognitive reserve hypothesis. Am J Psychiatry 154: 165-172.

69. Richards M, Sacker A (2003) Lifetime antecedents of cognitive reserve. J Clin Exp Neuropsychol 25: 614-624.

70. Stern Y, Zarahn E, Hilton HJ, Flynn J, DeLaPaz R, et al. (2003) Exploring the neural basis of cognitive reserve. J Clin Exp Neuropsychol 25: 691-701.

71. Bartrés-Faz D, Arenaza-Urquijo EM (2011) Structural and functional imaging correlates of cognitive and brain reserve hypotheses in healthy and pathological aging. Brain Topogr 24: 340-357.
72. Wilson R, Barnes L, Bennett D (2003) Assessment of lifetime participation in cognitively stimulating activities. J Clin Exp Neuropsychol 25: 634-642.

73. DeKosky ST, Scheff SW (1990) Synapse loss in frontal cortex biopsies in Alzheimer's disease: correlation with cognitive severity. Ann Neurol 27: 457464.

74. Satz P (1993) Brain reserve capacity on symptom onset after brain injury: A formulation and review of evidence for threshold theory. Neuropsychology 73 273-295.

75. Kesler SR, Adams HF, Blasey CM, Bigler ED (2003) Premorbid intellectual functioning, education, and brain size in traumatic brain injury: an investigation of the cognitive reserve hypothesis. Appl Neuropsychol 10: 153-162.

76. Mori E, Hirono N, Yamashita H, Imamura T, Ikejiri Y, et al. (1997) Premorbid brain size as a determinant of reserve capacity against intellectual decline in Alzheimer's disease. Am J Psychiatry 154: 18-24.

77. Andel R, Vigen C, Mack WJ, Clark LJ, Gatz M (2006) The effect of education and occupational complexity on rate of cognitive decline in Alzheimer's patients. J Int Neuropsychol Soc 12: 147-152.

78. Rush BK, Malec JF, Brown AW, Moessner AM (2006) Personality and functional outcome following traumatic brain injury. Rehabilitation Psychology 51: 257264.

79. Clement PF, Kennedy JE (2003) Wechsler Adult Intelligence Scale-third edition characteristics of a military traumatic brain injury sample. Mil Med 168: 10251028.

80. Morris PG, Wilson JT, Dunn LT, Teasdale GM (2005) Premorbid intelligence and brain injury. Br J Clin Psychol 44: 209-214.

81. Tate RL (2003) Impact of pre-injury factors on outcome after severe traumatic brain injury: Does post-traumatic personality change represent an exacerbation of premorbid traits? Neuropsychol Rehabil 13: 43-64. 